\title{
DA FICÇÃO DOS GÊNEROS À FICÇÃO LITERÁRIA: \\ UMA LEITURA DE $O$ FILHO DE MIL HOMENS
}

Emerson Silvestre é professor do Instituto Federal de Pernambuco (IFPE) e mestrando em Teoria da Literatura pela UFPE. E-mail: emesilvestre@gmail.com

\begin{abstract}
Resumo
Este artigo visa a realizar uma leitura do romance $O$ filho de mil homens, do escritor português Valter Hugo Mãe, com o intuito de observar como a ficcionalidade do texto nos auxilia a compreender e reinterpretar questões ligadas à construção das identidades de gênero e sexualidades na sociedade portuguesa. Para tanto, trabalhamos com a dimensão ficcional dessas identidades de gênero e com o conceito de homoafetividade para entender a construção do personagem homossexual do romance, bem como a sua relação com as demais personas do texto na formação de uma família de eleição, unida pelo afeto. Essas questões serão orientadas por estudos que teorizam a ficção enquanto estatuto e por textos que refletem a cerca da Teoria Queer e identidades de gênero.
\end{abstract}

\begin{abstract}
This article aims to take a reading of the novel O filho de mil homens, by Valter Hugo Mãe, in order to observe how the fictionality of the text helps us to understand and reinterpret issues linked to the construction of gender identities and sexualities in Portuguese society. To this end, we work with the fictional dimension of these gender identities and with the concept of homoaffectivity to understand the construction of the homosexual character of the novel, as well as his relationship with the other persons of the text in the formation of an election family, united by affection. These issues will be guided by theorized studies of fiction as statute and texts that reflect about the Queer Theory and gender
\end{abstract}

\section{1) Introdução}

Partindo da ideia sugerida por Searle (2002) de que nem toda ficção é literatura e para quem o estatuto do ficcional não é uma exclusividade do texto literário, a teoria da ficção pode ser entendida muito além do campo literário. Ela nos possibilita, por exemplo, relativizar o conceito de verdade e de real nas diversas instâncias do conhecimento se levarmos em consideração que a realidade de alguém ou de algo é sempre uma construção que parte do mundo experiencial para reinvestir esse mundo de novas possibilidades de percepção. Eis a ficção.

Sendo assim, podemos entender, também, a construção das identidades de gênero sob essa ótica: o gênero como constructo ficcional. Essa hipótese já vem sendo discutida pela Teoria Queer há algum tempo, mas não metodologicamente. Essa falta de rigor metodológico não nos parece um "problema", diríamos até que corresponde à postura queer dos teóricos que se propõem a discutir o assunto, isto é, como explica Judith Butler sempre que questionada sobre a dificuldade e a falta de objetividade da escrita de seus textos e de alguns outros estudiosos queer; se é para ser queer, comecemos por tornar queer a teoria. Em outras palavras, diz-se que a construção das identidades de gênero é um constructo ficcional, mas não se explica, metodologicamente, o porquê.

Um percurso metodológico interessante seria, talvez, entender como se dá a ficção da construção dos gêneros e a ficção do texto literário, observando as confluências e divergências entre as duas esferas e, finalmente, ver como a literatura opera essas questões para apresentar os gêneros por meio da ficção. Será este o percurso de escrita deste artigo. 
Não temos o intuito de "disciplinar" a Teoria Queer, pois acreditamos que ela, em si, já é algo paradoxal e por isso indisciplinável - como se pode querer colocar em uma perspectiva teórica algo que se quer estranho, indefinível e livre, o queer? -, a nossa discussão seguirá esse percurso apenas para fins metodológicos.

Para sedimentar nossa proposta, faremos uma leitura do romance $O$ filho de mil homens, de Valter Hugo Mãe, não como exemplo para a problemática teórica, mas como epicentro desta problemática, isto é, o romance como criador de um espaço de discussão sobre questões ligadas ao gênero. A análise se pautará, basicamente, na apresentação do personagem Antonino e de sua experiência como homossexual e de como o livro reabre a discussão sobre a homossexualidade em Portugal, um país em que as políticas de gênero são bem avançadas, mas a sociedade, de maneira geral, parece tratar as performances que estão fora do binômio masculino/feminino como invisíveis.

\section{2) As ficções do gênero e da literatura: diálogos}

É uma tarefa perigosa tentar dizer, com pretensa certeza, quando começou a se falar de representações de gênero na literatura. Contudo, com o advento dos estudos culturais, podemos apontar como um possível marco o momento em que a mulher decide reclamar seu lugar no campo das letras, isto é, quando as escritoras começam a buscar seu reconhecimento se manifestando contra a quase completa preponderância de escritores e críticos (homens) literários. Daí, a partir de mutações ideológicas, surgiram, dentre outros, os estudos feministas que visavam, também, à localização das escritoras dentro do que se convencionou chamar de cânone.

A partir disso, não somente a mulher e a escritura feminina, mas também as representações de gêneros destoantes do binômio masculino/feminino começaram a ser objetos de estudos. A Teoria Queer é o campo dos estudos culturais em que tais representações afloram mais intensamente:

\footnotetext{
"Queer" pode funcionar como substantivo, adjetivo ou verbo, mas em qualquer caso se define contra o "normal" ou normatizador [...] O termo descreve um leque diverso de práticas e prioridades críticas: leituras de representação do desejo pelo mesmo sexo em textos literários, filmes, música e imagens; análise das relações de poder sociais e políticas da sexualidade; críticas do sistema sexo-gênero; estudos de identificação transsexual e transgênero, de sadomasoquismo e de desejos transgressivos (SPARGO, 2006, p. 8-9).
}

A Teoria Queer, bem como o feminismo, são respostas às imposições que vêm juntamente com a concepção de identidades enrijecidas. A identificação de traços e comportamentos queer em obras de arte, na sociologia, na psicanálise veio à tona, mais fortemente, através dessa teoria, mas é importante observar que sempre houve a necessidade de externar essas outras possibilidades de identidades, sobretudo na arte, campo imagético por excelência.

Dessa maneira, não podemos concluir que a relação literatura/gênero se faça somente pela necessidade de se pensar em uma escritura feminina, ou na representação da 
mulher ou de outras minorias sexuais na literatura, seja como autores, seja como personagens viventes de uma diegese. Gostaríamos de explorar outros limites dessa relação e, para tanto, nos parece imprescindível levantar alguns pontos referes à construção de identidades de gênero e tentar fazer um paralelo com a literatura.

Começaremos, pois, pela definição de gênero. Segundo Judith Butler - uma das principais representantes da Teoria Queer - a perspectiva da identidade de gênero deve ser repensada. A visão biológica e inata dos gêneros, isto é, a determinação do gênero de acordo com o sexo (homem = masculino; mulher $=$ feminino) não se sustenta, pois ela não daria conta, por exemplo, da transexualidade e do travestismo: "Tais limites se estabelecem sempre nos termos de um discurso cultural hegemônico, baseado em estruturas binárias que se apresentam como a linguagem da racionalidade universal" (BUTLER, 2008, p. 28).

Perante esse impasse, Butler sugere a construção das identidades de gênero como um processo discursivo, isto é, o gênero se forma por meio da linguagem - ou do que a linguagem faz com o corpo - sendo, portanto, um processo sem origem e nem fim que se constrói por uma sequência de atos. Esses atos proporcionam o que Butler chama de performatividade - tomando emprestado um conceito de Austin e da teoria dos atos de fala -, ou seja, o gênero é o que a linguagem permite o corpo fazer:

\begin{abstract}
Nesse sentido, o gênero não é um substantivo, mas tampouco é um conjunto de atributos flutuantes, pois vimos que seu efeito substantivo é performativamente produzido e imposto pelas práticas reguladoras da coerência do gênero. [...] nós afirmaríamos como corolário: não há identidade de gênero por trás das expressões do gênero; essa identidade é performativamente constituída, pelas próprias "expressões" tidas como resultados (BUTLER, 2008, p.48. Grifos da autora).
\end{abstract}

Isto nos leva a crer que não se concebe um gênero a partir do sexo biológico, mas se modifica a linguagem com que os gêneros são construídos. Dessa forma, por exemplo, o próprio gênero feminino surge de uma especificidade linguística que modifica o gênero masculino dominante, o mesmo ocorre com as identidades intergenéricas (transexuais, hermafroditas, drags, gays e lésbicas, de performance disforme ao seu gênero prédeterminado), todos eles estudados por Butler e pela Teoria Queer.

Levando-se em consideração a perspectiva discursiva de gênero - que, segundo Butler, não se restringe apenas ao gênero, mas também à própria construção do sexo e do corpo, o que já fora, de certa forma, iniciado por Foucault -, quando relacionamos gênero e literatura, podemos dizer que estamos tratando de assuntos que circulam na esfera da linguagem ficcional, pois tal perspectiva cria outras possibilidades de realidades.

Quando dissemos anteriormente que não se cria um gênero de um vácuo epistemológico, mas se modifica as concepções já existentes - a concepção da heteronormatividade e da masculinidade/feminilidade compulsórias, por exemplo -, acabamos por fazer uma aproximação com o discurso ficcional da literatura. Se 
pensarmos que o texto literário também opera uma sistemática semelhante: a realidade do texto ficcional não surge de um vácuo, ou de um mundo absolutamente estranho, na verdade, ele organiza e apresenta o mundo e o real de outras maneiras, por isso cria-se o efeito de "coisa nova", e, compartilhando da ideia de "que a ficção literária não é miragem do real, mas um outro modo de sua apreensão pelo discurso" (COELHO, 2002, p.6), temos estabelecido uma aproximação entre gênero e literatura transpassada pela ficção.

O gênero está encriptado no corpo e esse corpo é construído por linguagem que por sua vez só faz sentido quando posto em circulação numa esfera discursiva a qual pressupõe, pelo menos, duas leituras: do próprio corpo e o que se fala do corpo, isto é, o corpo e como os outros lêem esse corpo (no qual está impresso o gênero).

Uma equação semelhante pode ser feita quando nos detemos à questão da literatura: também feita por/na linguagem, o texto literário (re)cria a vida, produzindo novas possibilidades de real, por meio do que Iser e sua Estética do Efeito, por exemplo, denominam de fingimento:

Se os textos ficcionais não são de todo isentos de realidade, parece conveniente renunciar a este tipo de relação opositiva como critério orientador para a descrição dos textos ficcionais, pois as medidas de mistura do real com o fictício, neles reconhecíveis, relacionam com frequência elementos, dados e suposições. [...] Como o texto ficcional contém elementos do real sem que se esgote na descrição deste real, então o seu componente fictício não tem o caráter de uma finalidade em si mesma, mas é, enquanto fingida, a preparação de um imaginário. (ISER, 2002, p. 957).

Segundo essa perspectiva, a literatura não é apenas uma linguagem estranha, desviante - como queriam uma parcela dos formalistas russos - mas é também e, sobretudo, capaz de "desrealizar" o real e moldá-lo num universo diferente (diegese). Essa relação, por sua vez, não se faz por meio da anulação do real concreto, ou da simples representação dele no universo literário, mas sim pela recriação e reapresentação desse real. Isso nos permite dizer que mesmo a ideia estritamente mimética da literatura (defendida por muitos) deve ser compreendida, também, como uma possibilidade criativa, uma vez que seleciona dados da realidade empírica para ressignificá-los.

A linguagem literária, segundo essa perspectiva, não é uma nova língua, ou seja, para se ler um texto ficcional não é necessário aprender um novo código linguístico, pois usamos a mesma língua na ficção e na linguagem comum. Tampouco somos obrigados a conhecer universos que nos são completamente estranhos. A ficção é experiência do mundo, logo, por mais distante que o texto possa parecer estar da realidade empírica os contos de fada ou o modo fantástico da escrita literária, por exemplo - sempre haverá uma ancoragem no real.

A diferença entre a palavra no discurso comum e a palavra no discurso ficcional (na nomenclatura de Searle, convenção vertical e convenção horizontal, respectivamente) 
talvez resida no fato de que no texto literário os significados ainda são literais, mas o compromisso com esses significados podem ser subvertidos:

Tais convenções horizontais não são regras do significado; elas não são parte da competência semântica do falante. Dessa maneira, não modificam nem mudam o significado de nenhuma das palavras ou de outros elementos da língua. O que fazem é habilitar o falante a usar palavras em seus significados literais sem assumir os compromissos normalmente exigidos por esses significados (SEARLE, 2002, p.107108).

Sendo assim, quando dizemos que não se constrói um gênero completamente novo segundo os estudos de Butler e da Teoria Queer - queremos dizer que o gênero é uma ficção que realiza de outra maneira, ou de maneira avessa a pré-determinação hegemônica dos gêneros. Em relação à literatura: para que ela exista é preciso não exterminar a realidade, mas ressignificá-la, apresentá-la de outras formas.

A Estética do Efeito diz que o que faz um texto ser literário é justamente a possibilidade de ficcionalizar, de fingir. A construção discursiva do gênero, por sua vez, calcada no conceito de performatividade, pode manipular a linguagem do corpo de modo que construa identidades de gênero que não sejam, necessariamente, a do homem masculino e da mulher feminina. Por síntese, a construção de um eu fictício - seja ele na literatura ou na perspectiva da construção discursiva dos gêneros - corrobora a ideia de que a performatividade do gênero e a instituição do ficcional na literatura são inscrições no campo discursivo do "como se" e do "fingimento".

Searle também compactua dessa ideia de fingimento: "fingir fazer ou ser alguma coisa é envolver-se numa encenação, é agir como se estivesse fazendo ou fosse esse coisa, sem nenhuma intenção de enganar" (SEARLE, 2002, p. 105. Grifos do autor). Quando pensamos no conceito de performatividade da Teoria Queer, temos que pensar em dois pontos: 1) os gêneros serão sempre performativos por serem construções linguísticas; 2) por serem performativos, estarão disponíveis para utilização e as pessoas são livres para utilizá-los como as convém.

A partir disso é que será possível "subverter" essa performatividade quando, por exemplo, um homem, que compulsoriamente deveria respeitar a performatividade do masculino, decide ou sente a necessidade de não ser tão masculino assim. Essa subversão é que cria o efeito de encenação, o sujeito parece estar fingindo ser o que não é. Entretanto, essa encenação não quer parecer mentira ou engano, mas tão somente a realidade. Discutir o limite dessas performatividades de gênero e concebê-las como construções ficcionais é, talvez, o principal objetivo da Teoria Queer e um grande desafio, uma vez que essa discussão estimula a desrealização do conceito de masculino e feminino para dar lugar às múltiplas percepções de gêneros e sexualidades.

A literatura parece enfrentar esse mesmo desafio. É comum ouvir dizer que literatura é mentira, que nada do que está nos livros deve ser levado a sério, que, por ser mentira, deve-se mesmo evitar a leitura. Basta nos lembrarmos da República de Platão e de como 
os poetas foram expulsos da sociedade ideal, ou de todos os livros queimados por serem acusados de subversão.

Os exemplos são muitos, mas é necessário conhecer o estatuto do ficcional - mais uma vez reforçamos a compreensão da ficção além do campo literário - para entender que:

Por tanto, las ficciones no son el lado irreal de la realidad ni, desde luego, algo opuesto a la realidad, como todovía las consideran nuestro "conocimiento tácito"; son más bien condiciones que hacen posible la producción de mundos, de cuya realidad, a su vez, no puede dudarse. (ISER, 1997, p. 45).

Perante o exposto até aqui, a relação entre gênero e literatura, portanto, não está apenas no nível superficial de quem escreve o texto literário (se homem, mulher, ou as minorias sexuais), ou das representações femininas e queers nos textos literários (literatura como espelho do mundo), mas tal relação pode ser entendida como dispositivo do próprio fazer literário, e alcançar outros universos (diegético, psicanalítico, social), quando relacionamos a natureza discursiva do gênero com a natureza ficcional da literatura, ambas calcadas no trabalho "metamorfosedor" da linguagem.

Podemos ainda sustentar nossa hipótese no fato de que o discurso literário, inevitavelmente, desperta o interesse dos demais discursos aproximados das humanidades, seja por ser um processo cultural, ou por trabalhar, de uma forma ou de outra, com o material da realidade social: "A sua [do literário] inserção no interior dos mais variados textos atua como fator preponderante para o literário ser considerado na função articuladora, imagística e conceitual” (SOUZA, 2002, p. 24).

Ainda sobre o ficcional, tanto do literário quanto da produção de gêneros, podemos nos servir do respaldo indicado por Souza quando diz que: "O reconhecimento do estatuto ficcional das práticas discursivas e da força inventiva de toda teoria nos alerta para a íntima relação entre o artístico e o cultural no lugar da exclusão de um pelo outro" (2002, p. 24).

Após nossa tentativa de colocar a Teoria Queer em diálogo com os estudos da ficção literária, gostaríamos de realizar um corte epistemológico e focar nossa discussão em Portugal para tentar compreender como se comporta a ficção dos gêneros neste país e qual a contribuição da literatura nessa discussão.

\section{3) A ficção dos gêneros: $o$ caso português}

Como foi dito na introdução deste artigo, além do que já fora discutido sobre a ficção literária e a ficção dos gêneros, faremos uma breve análise do romance de Valter Hugo Mãe para observar como a ficção permite ao texto resolver, ou apresentar problemas que normalmente não são tratados com frequência em Portugal. Antes disso, no que concerne à discussão sobre as identidades de gênero é necessário apontar algumas situações que nos parecem complexas e contraditórias. 
O esforço do movimento intitulado LGBT (lésbicas, gays, bissexuais e transgêneros) e dos intelectuais portugueses atuantes no campo da Teoria Queer localizam-se nos diversos instrumentos de ativismo que começam a surgir, tardiamente, em 1990 como sugere Santos e Fontes (2006). Segundo os pesquisadores, que adotam uma postura da sociologia pública, e que acreditam na articulação entre sociologia, ativismo e estudos queer, tal discussão: “[...] permitirá multiplicar os espaços de debate e intervenção sociopolítica em temas historicamente excluídos da reflexão democrática e confinados ao espaço privado, clandestino e/ou marginal onde tradicionalmente se encerram as sexualidades" (SANTOS; FONTES, 2006, p.98).

No que se refere à relação entre Teoria Queer e estudos literários em Portugal, o campo pode ser considerado ínfimo quando comparado às pesquisas realizadas no Brasil, onde, por exemplo, escritores como Caio Fernando Abreu, Hilda Hilst e Dalton Trevisan têm suas obras analisadas, frequentemente, pela ótica queer. Como sugere Cecília Barreira, em leitura sobre a poesia de Isabel de Sá:

A escrita gay e lésbica encontram-se numa situação de não nomeação, porque é inexistente. Existem estudos no mundo anglo-saxônico ou mesmo em França e Espanha sobre essa escrita, mas em Portugal não pode falar-se de tabu porque nem sequer é reconhecível (BARREIRA, 2010, p.22).

Essa falta de reconhecimento e pretensa inexistência das identidades e sexualidades desviantes do eixo masculino/feminino e da heterossexualidade compulsória podem ser facilmente percebidos por meio dos indicadores e das pesquisas acadêmicas, o que nos leva a um paradoxo: em 2010 o Estado português assinou a lei que autoriza a união civil entre pessoas do mesmo sexo. Ora, se o próprio Estado reconhece essas outras identidades de gênero e de sexualidade, por que elas ainda são tratadas como inexistentes pela sociedade portuguesa?

Essa é uma pergunta difícil de ser respondida, mas podemos apontar alguns caminhos que nos auxiliam a pensá-la. Em primeiro lugar não se pode negar o fato de ser Portugal um dos países mais católicos do mundo e que o cristianismo sempre condenou a homossexualidade comparando-a, entre outras coisas, ao demoníaco e ao patológico. Essa herança católica é ainda muito forte e de alguma forma está associada a essa invisibilidade da qual falamos. Outra possível resposta reside no fato da aparente "modernização" do país que, coincidentemente, seguiu a onda de outros países sobretudo os da Europa - no mesmo ano ou logo após tais países terem legalizado a união civil igualitária.

Outro paradoxo que acompanha esta discussão está no baixo número de crimes de homofobia no país. Ao contrário do que acontece no Brasil e nos EUA, onde as políticas LGBT são reivindicadas mais abertamente, mas onde os índices de crimes homofóbicos são alarmantes, em Portugal a invisibilidade parece refletir nessa ausência de violência, o que nos parece contraditório visto o que foi dito acerca da resistência provocada pela religião. 
Como se vê, Portugal é um caso atípico. Do ponto de vista legal parece haver avanços, mas do ponto de vista social impressiona a destreza com que se apaga a homossexualidade e outras discussões que envolvem as categorias de gênero e sexualidade. É nesse tocante que a arte desempenha um papel importantíssimo, o de tentar resolver este dilema: trazer para o debate estes temas silenciados, essas minorias silenciadas.

O romance de Valter Hugo Mãe é um desses exemplos de política da escrita, segundo o conceito de Rancière (1995), não a política na literatura, mas a política da literatura que é capaz de contestar para reorganizar. Nesse momento, o que se disse sobre a ficção parece fazer todo o sentido, na verdade, é através dela que se torna possível debater tais assuntos.

\section{4) Considerações acerca de $O$ filho de mil homens}

Este romance de Valter Hugo Mãe explora a homossexualidade por meio da personagem Antonino, contando, à semelhança de uma fábula, sua história desde a infância até a formação de uma família. Podemos dizer que o romance explora dois temas que se entrelaçam: a homossexualidade e a construção de família.

Diferentemente do tipo mais comum de homorrepresentação ficcional, isto é, a forma como a homossexualidade se apresenta no texto literário, o filho de mil homens não aborda o homoerotismo. Não existe no romance nenhuma imagem que remonte a relação sexual entre dois homens ou duas mulheres; o que se tem, na verdade, é uma aproximação do conceito de homoafetividade.

Vale salientar que os estudiosos das homorrepresentações ficcionais fazem, não raramente, o equívoco de rotular os textos em literatura gay, ou literatura homoerótica. Não é objetivo deste artigo abordar as discussões acerca das diferentes formas de apresentação das sexualidades na ficção literária, mas gostaríamos de ressaltar que em $o$ filho de mil homens percebe-se claramente que o que se apresenta nada tem a ver com a erotização do sexo.

Nesta leitura, preferimos nos referir à homoafetividade e não ao homoerotismo por entendermos que não há, no romance, nenhuma passagem que retrate o relacionamento erótico entre indivíduos homo-orientados. O que há, de fato, é a perspectiva da homoafetividade entendida em sua concepção mais abrangente: Antonino reconhece-se homossexual, mas na fábula do texto, o que prevalece é o aspecto afetivo e identitário dessa dimensão, isto é, a inscrição da homossexualidade ultrapassa o limite do corpo para alcançar outros aspectos desta relação.

Denilson Lopes (2002) defende com explícita convicção a homoafetividade e acredita que o termo ajuda a compreender a homorrepresentação ficcional (ou a homotextualidade literária, como ele prefere dizer) por outros vieses que não apenas os pautados na relação erotizada entre corpos masculinos, segundo ele: 
[...] defendo uma política, uma ética e uma estética da homoafetividade. Não pretendo apenas cunhar mais um termo, mas penso que falar em homoafetividade é mais amplo do que falar em homossexualidade ou homoerotismo, vai além do sexo-rei, bem como é um termo mais sensível para apreender as fronteiras frágeis e ambíguas entre a homossexualidade e a heterossexualidade (LOPES, 2002, p.37).

Como já se disse, no romance não nos deparamos com nenhuma cena homoerótica. Mesmo no único vislumbre em que Antonino parece se interessar por um homem, já no final da narrativa, predomina a homoafetividade como tentamos delinear. Nesta passagem, o narrador conta a reação de Antonino ao encontrar o estranho homem que se aproximara interessado em comprar algum produto de sua fazenda:

Se fosse pelos ovos, pensou Antonino, então era só ir buscá-lo, que até lhos dava. Se fosse por um frango, então era só ir buscá-lo, que até lho dava. Se fosse por uma conversa, então podia dizer, mas talvez o Antonino, estremecido, não conseguisse responder nada. Adoraria, contudo, que fosse por uma conversa (MÃE, 2011, p. 191).

$\mathrm{O}$ que queremos destacar com a insistência em demonstrar a falta de registro homoerótico no texto de Mãe é justamente esta outra dimensão da homossexualidade: a afetividade por trás dos corpos. Esta afetividade é ainda reforçada no romance quando levamos em consideração a outra temática abordada pelo autor: a construção da família.

A concepção de família é outro ponto caro ao escritor e especificamente em o filho de mil homens. Crisóstomo, Camilo, Isaura e Antonino são uma família inventada. Mosaico de famílias inexistentes (Crisóstomo, que aos quarenta anos não teve a felicidade de ter um filho, e Camilo, órfão de duas famílias), ou da desestrutura familiar (Isaura, filha de uma mãe que enlouquece e mulher que nunca conseguiu um casamento, e Antonino único filho homossexual de uma mãe solteira). Nessas circunstâncias, vemos as personagens criando uma família que, mesmo não sendo consanguínea, encontra, na aceitação um do outro, o acolhimento ideal para sua formação.

Ambientado em um espaço rural, a tradição da família patriarcal com funções políticas, administrativas e afetivas regradas cede lugar para uma nova concepção na qual cuidado, compreensão e aceitação - incluindo a figura de um homossexual como membro participante dela - são as bases fundamentais de sua construção.

A compreensão pela qual é submetido Antonino surge, no livro, no mesmo instante em que as outras personagens reconhecem-se na mudez da solidão que só é arrematada pelo amor. Existe, dessa forma, um percurso em o filho de mil homens no qual a visão preconceituosa, e quase sempre com bases religiosas (cristãs), vai se modificando na medida em que os outros personagens descobrem o amor e constituem-se enquanto uma família.

Esse percurso pode ser facilmente identificado no decorrer do texto, pois, como foi dito, este romance é narrado de maneira fabular, isto é, fica muito evidente o intuito do autor em aplicar uma moral, a saber, explorar a experiência homossexual de Antonino para "educar" Camilo, o órfão que foi ensinado a odiar "os maricas". Este intuito é 
projetado, inevitavelmente, para o leitor que se depara com uma tentativa explícita de apresentação da homoafetividade a qual explora outra dimensão da relação homorientada: a afetiva e não a erotizada.

No início do romance nos deparamos com narrações nas quais se evidenciam a concepção demonizada e patológica da homossexualidade:

\begin{abstract}
Parecia uma menina quando dizia algumas palavras, parecia que, distraindo-se, gesticulava demasiado [...] A vizinha, mais fácil de dizer as coisas, contava-lhe que pelas redondezas os poucos casos daqueles tinham sido tratados em modos. Uns racharam os filhos ao meio, outros mandaram-nos embora espancados e sem ordens para voltar, e um homem até subiu pelo cu acima do filho uma vara grossa e pô-lo ao dependuro para todos verem (MÃE, 2011, p. 87).
\end{abstract}

Esta atmosfera persegue Antonino obrigando-o a se casar com Isaura por aparência, período que denominaremos de incubação. Após isso, ele vê-se obrigado a fugir deixando Isaura desposada para retornar quando ela já se apaixonara por Crisóstomo que por sua vez já havia tomado Camilo como seu filho. O retorno de Antonino é como um corpo estranho para a família de eleição que começava a se formar, sobretudo para Camilo que como já se disse fora educado pelo seu primeiro pai que o disse "que o amor era todo da família ou dos homens com as mulheres. Como se os maricas não fossem familiares, não fossem nascidos de pai e mãe, não pertencessem a ninguém" (MÃE, 2011, p. 108).

Ao longo do enredo podemos divisar alguns estágios da construção ficcional do gênero de Antonino. O primeiro é o reconhecimento, ainda na infância, de que ele não correspondia à masculinidade pretensamente atrelada ao seu sexo biológico. A este reconhecimento está ligado o discurso homofóbico do primeiro pai de Camilo e da população local em relação a Antonino. Em segundo lugar está a despatologização da homossexualidade, isto é, Crisóstomo, Camilo e Isaura se dão conta de que o fato de Antonino não ser masculino como a maioria dos homens não o torna uma pessoa doente. Nesse segundo estágio, desenha-se a ficcionalidade do gênero em que a masculinidade é relativizada e a performance de Antonino funciona como dispositivo criativo na construção do seu gênero.

\A leitura que se faz da identidade de Antonino fora da perspectiva patológica só acontece próxima ao fim do romance quando Camilo parece acolher o seu "tio" como membro da família, e depois de perceber que ele não era uma ameaça para os seus novos pais. Antonino então percebe que: "Pertenciam-se e comunicavam entre si pela intensidade dos sentimentos. Tinham inventado uma família” (MÃE, 201, p. 199).

Do ponto de vista da ficção, podemos resgatar alguns postulados que dizem respeito tanto ao literário quanto à ficção dos gêneros. Primeiramente, percebe-se no decorrer da leitura que o romance de Mãe localiza-se em uma paisagem interiorana e em um tempo que não nos parece contemporâneo; essas condições tornam a apresentação da homossexualidade e da homoafetividade ainda mais complexas pelos motivos aparentes 
do conservadorismo de ideais mais engessados acerca desses temas nas sociedades rurais.

Dessa maneira, o romance, por meio da ficção, seleciona os dados do mundo empírico para alocá-los em uma atmosfera ainda mais hostil que a faceta urbana da sociedade portuguesa. Elevar tais discussões ao nível da ficção permite "resolver" os paradoxos (citados na seção anterior) que envolvem as construções de gênero e sexualidades em Portugal. Optar pela apresentação da homoafetividade e pela construção da família fora do eixo heteronormativo e patriarcal revela certa ousadia se pensarmos na pretensa invisibilidade com que tais temáticas são tratadas no país.

Em segundo lugar, a abordagem da homossexualidade pelo viés da homoafetividade vinculada à construção de família permite repensar a dinâmica dos gêneros e da sexualidade. Antonino é o típico "maricas" silenciado pela maioria heterossexual e heteronormativa. Isaura é a típica mulher inscrita sob o signo da submissão e da injustiça pelo simples fato de ser mulher. Ao dar visibilidade a essas personagens, $O$ filho de mil homens retoma o debate sobre a dimensão especulativa acerca dos gêneros, que leva em consideração os dispositivos ficcionais para redimensionar concepções compulsórias à normalidade instituída socialmente.

\section{5) Considerações Finais}

Este artigo buscou entrever que o romance $O$ filho de mil homens, de Valter Hugo Mãe, é uma tentativa de apresentar a homoafetividade dentro de uma sociedade que prefere não tocar no assunto. Como vimos, em Portugal falar em homossexualidade é falar sobre a inexistência. Apesar dos baixos índices de crimes homofóbicos, as políticas pró-homossexualidade encontram dificuldade para circular nas esferas sociais.

Portanto, acreditamos que falar em Teoria Queer ao ler o romance em questão é uma forma de abrir o diálogo acerca das sexualidades em trânsitos que encontram nos discursos das artes mais espaço, já que socialmente e empiricamente falando o lugar de tais sexualidades, em Portugal, é no armário.

Só foi possível chegar a tais conclusões quando lançamos mão da teoria da ficção para explicar os fenômenos literários e sociais que o romance aborda. Ao assumirmos as posturas teóricas dos estudiosos da ficção que selecionamos, podemos considerar que a ficção dos gêneros, através da literatura, encontra um terreno propício para sua apresentação. Não se trata apenas do romance em questão, mais de uma maneira geral os temas que são tabus sociais parecem encontrar no campo da ficção literária um espaço propício de circulação.

Quando pensamos na ficção como procedimento de desrealização do real e construção de outras realidades e verdades, percebemos que o romance de Mãe instaura duas possibilidades de leitura do universo português: 1) torna visível o tema acerca das outras identidades de gênero que fogem ao binarismo masculino/feminino; 2) à semelhança de uma fábula, a narrativa proporciona uma revisão do conceito de família e de afetividade. 
A ficção, portanto, possibilita a criação do que Doležel (1997) chama de mundos possíveis. Desprendida de uma semântica mimética, na qual os textos literários necessariamente deveriam ser tributários de uma ancoragem direta com um real universal, a ficção parece estar melhor relacionada com a criação de outros mundos possíveis que, apesar da ancoragem no real, não querem ser espelho da realidade, mas a possibilidade de uma realidade refletida no espelho do texto: "Una teoría englobadora de las ficciones literarias surge de la fusíon de la semántica de los mundos possibles con la teoría del texto" (DOLEŽEL, 1997. p. 78).

Sendo assim, o mundo possível criado por Valter Hugo Mãe em o filho de mil homens desestabiliza as concepções acerca de gêneros e sexualidades que estão fincadas na sociedade empírica, especificamente na sociedade portuguesa. Essa desestabilização se dá por meio da ficção dos gêneros sugerida pela Teoria Queer em diálogo com a própria ficção literária. Conclui-se que o estatuto do ficcional proporciona o diálogo fronteiriço entre os campos do saber, fazendo da literatura uma ferramenta estética de discussão política.

\section{Referências Bibliográficas}

BARREIRA, Cecília. Um caso de escrita de orientação sexual em Portugal: a poesia de Isabel de Sá. Disponível em: <http://www.ufjf.br/revistaipotesi/files/2010/02/Umcaso-de-escrita.pdf>. Acesso em: 05 de janeiro de 2015

BUTLER, Judith. Problemas de gênero: feminismo e subversão da identidade. Tradução de Renato Aguiar. Rio de janeiro: Civilização Brasileira, 2008.

COELHO, Ruy. Ficção e realidade. Disponível em: <http://www.usp.eca.br/associa/cesa/revista/revista4/ficcaoerealidade.html >. Consulta em: 25 de dezembro de 2014.

DOLEŽEL, Lubomir. Mímesis y mundos posibles. In: DOLEŽEL, L.et al. Teorías de la ficción literária. Compilação de textos, introdução e bibliografia de Antonio Garrido Domínguez. Madrid: Arco/Libros S.L., 1997.

ISER, Wolfgang. Os atos de fingir ou o que é fictício no texto ficcional. In: LIMA, Luiz Costa (org.). Teoria da Literatura em suas fontes, vol. 2. Rio de Janeiro: Civilização Brasileira, 2002.

, Wolfgang. La Ficcionalización: dimensión antropológica de las ficciones literatias. In: DOLEŽEL, L.et al. Teorías de la ficción literária. Compilação de textos, introdução e bibliografia de Antonio Garrido Domínguez. Madrid: Arco/Libros S.L., 1997. 
LOPES, Denilson. O homem que amava rapazes e outros ensaios. Rio de Janeiro: Aeroplano, 2002.

MÃE, Valter Hugo. O filho de mil homens. São Paulo: Cosac Naify, 2011.

RANCIÈRE, Jacques. Políticas da escrita. Rio de Janeiro: Ed. 34, 1995.

SANTOS, Ana Cristina; FONTES, Fernando. Descobrindo o arco-íris: Identidades homossexuais em Portugal. Disponível em: <http://www.aps.pt/cms/docs_prv/docs/DPR462e057050922_1.PDF>. Acesso em: 5 de janeiro de 2015.

SEARLE, John R. Expressão e significado: estudos da teoria dos atos de fala. Tradução de Ana Cecília G. A. de Camargo, Ana Luiza Marcondes Garcia. São Paulo: Martins Fontes, 2002.

SOUZA, Eneida Maria de. Crítica Cult. Belo Horizonte: Editora UFMG, 2002.

SPARGO, Tamsim. Foucault e a teoria queer. Tradução de Vladimir Freire. Ed. UFJF. Rio de Janeiro: Pazulin; Juiz de Fora, 2006. 